\title{
Synergistic cell growth inhibition by the combination of amrubicin and Akt-suppressing tyrosine kinase inhibitors in small cell lung cancer cells: Implication of c-Src and its inhibitor
}

\author{
YASUTO UEDA $^{1}$, TADASHI IGISHI ${ }^{1}$, KIYOSHI HASHIMOTO ${ }^{1}$, HISASHI SUYAMA ${ }^{1}$, KUNIO ARAKI $^{2}$, \\ TAKASHI SUMIKAWA ${ }^{1}$, KENICHI TAKEDA $^{1}$, HIROFUMI NAKAZAKI $^{1}$, KEIJI MATSUNAMI $^{1}$, \\ MASAHIRO KODANI $^{1}$, YASUSHI SHIGEOKA ${ }^{1}$, SHINGO MATSUMOTO ${ }^{1}$ and EIJI SHIMIZU ${ }^{1}$ \\ ${ }^{1}$ Division of Medical Oncology and Molecular Respirology, Faculty of Medicine, Tottori University, Yonago 683-8504; \\ ${ }^{2}$ Department of Surgery, National Hospital Organization, Matsue National Hospital, Matsue 690-8556, Japan
}

Received October 21, 2008; Accepted December 15, 2008

DOI: 10.3892/ijo_00000195

\begin{abstract}
Small cell lung cancer (SCLC) is one of the intractable malignancies. The goal of this study was to clarify whether Akt activity is involved with chemo-resistance and to improve the sensitivity of SCLC cells to the current standard chemotherapeutic drugs with agents that are expected to suppress Akt activity through tyrosine kinase inhibition. Although Akt activity seemed to be involved with the sensitivity of SCLC cells to chemotherapeutic agents (cisplatin, etoposide, SN38 and amrubicin), in Akt-activated N417 cells, only amrubicin exerted synergistic cell growth inhibition when combined with an Akt inhibitor, LY294002. A non-specific tyrosine kinase inhibitor, genistein, suppressed Akt and showed synergistic interaction in combination with amrubicin in N417 cells. Among tyrosine kinases (insulin-like growth factor I receptor, c-Kit and c-Src), only c-Src was activated in N417 cells compared with Akt-inactive H209 cells. A c-Srcspecific inhibitor, PP2, and a clinically available multi-tyrosine kinase inhibitor, dasatinib, suppressed Akt activity in parallel with c-Src inhibition. Both PP2 and dasatinib exerted synergistic growth inhibition of N417 cells in the combination with amrubicin. In immunohistochemical analysis, c-Src was expressed in 17 of 19 of the SCLC tumor tissues. These observations suggested that Akt suppression enhances the cytotoxicity of amrubicin, and for the purpose of Akt suppression, c-Src is a promising target in SCLC.
\end{abstract}

\section{Introduction}

Lung cancer is a common fatal malignancy in the world. Small cell lung cancer (SCLC) accounts for 13 to $20 \%$ of lung

Correspondence to: Dr Tadashi Igishi, Division of Medical Oncology and Molecular Respirology, Faculty of Medicine, Tottori University, Yonago 683-8504, Japan

E-mail: igishi@med.tottori-u.ac.jp

Key words: small cell lung cancer, Akt, c-Src, dasatinib, amrubicin cancer cases and is characterized by rapid progression and metastasis (1). Most patients with SCLC show favorable responses to first-line chemotherapy. A combination chemotherapy of cisplatin (CDDP) and etoposide (VP16) or irinotecan is currently a standard first-line chemotherapeutic regimen $(2,3)$ and the response rate to these treatments is $>80 \%$ (2). Despite these very good responses to first-line chemotherapy, recurrence after a short term is frequent in patients with SCLC (4) and these patients will require second-line treatment with a topoisomerase I inhibitor, topotecan $(5,6)$, or a totally synthetic 9-amino-anthracycline, amrubicin (AMR) (4,7). However, even with these clinically available drugs, the prognosis of patients with SCLC is poor (8). Accordingly, novel drugs that are effective against SCLC or new treatment strategies are needed to improve the therapeutic outcome of SCLC.

Recent research has provided evidence that several alterations in intracellular signaling are involved in the development of cancer and tumor progression (9). The phosphatidylinositol 3-kinase (PI3K)/Akt (also known as protein kinase B) pathway is one of the best-studied pathways and is believed to be a potential target of cancer therapy (10). As a biological function, the proliferative and anti-apoptotic effects of Akt-mediated signaling have been established through extensive studies $(11,12)$. Phosphorylated Akt was detected in $68 \%$ of the tumor specimens from SCLC patients (13), suggesting a high incidence of activated $\mathrm{PI} 3 \mathrm{~K} /$ Akt pathway in SCLC cells. Activated Akt is also proposed to contribute to increased resistance to radiation and chemotherapy in SCLC cells (14). Accordingly, the suppression of activated Akt may be a strategy to overcome drug resistance and to improve the treatment outcome in SCLC.

In general, the PI3K/Akt pathway is regulated by growth factors and their receptor tyrosine kinases. In SCLC, c-Kit and its ligand, stem cell factor, have attracted much attention as therapeutic targets that regulate intracellular signals, including the PI3K/Akt pathway (15). Unfortunately, however, imatinib, which inhibits c-Kit, failed to show clinical benefits as a single agent or in combination with other conventional chemotherapeutic agents (16-18). Thus, it 
is still important to find an Akt-suppressing agent that is clinically applicable in the treatment of SCLC.

In the process of assessing the association between Akt activity and sensitivity to conventional cytotoxic drugs in SCLC cells, we found that activated Akt is strongly related to AMR resistance and synergistic cell growth inhibition by the combination of AMR and Akt-suppressing agents. Furthermore, Akt activity was effectively suppressed by c-Src inhibitors, including a clinically available multi-tyrosine kinase inhibitor, dasatinib. In the present study, we describe the potential of c-Src as a molecular target in the treatment of SCLC.

\section{Materials and methods}

Chemicals and reagents. Amrubicin (a gift from Nippon Kayaku Co., Ltd., Tokyo, Japan) was dissolved in distillated water and stored at $-20^{\circ} \mathrm{C}$. A stock solution of CDDP (a gift from Nippon Kayaku Co., Ltd) was reconstituted with water, diluted in $0.9 \%$ sodium chloride solution and stored at $-20^{\circ} \mathrm{C}$. VP16 (Wako Pure Chemical Industries, Ltd., Osaka, Japan); an active metabolite of irinotecan, 7-ethyl-10hydroxycamptothecin (SN38) (a gift from Daiichi Sankyo Co., Ltd., Tokyo, Japan); BMS-354825 (dasatinib) (a gift from Bristol-Myers Squibb, New York, NY); 2-(4Morpholinyl)-8-phenyl-4H-1-benzopyran-4-one (LY294002) (Sigma-Aldrich Japan, Tokyo, Japan); 4',5,7-trihydroxyisoflavone (genistein); and 4-amino-5-(4-chlorophenyl)-7-(tbutyl)pyrazolo[3, 4-d]pyrimidine (PP2) (Calbiochem, San Diego, CA) were dissolved in dimethyl-sulfoxide and stored at $-20^{\circ} \mathrm{C}$. 3-(4,5-dimethyl-thiazol-2-yl)-2, 5diphenyltetrazolium bromide (MTT) (Wako Pure Chemical Industries, Ltd) was dissolved in phosphate-buffered saline (PBS) and stored at $-20^{\circ} \mathrm{C}$.

Cells. The human SCLC cell lines N417, H209 and H69 were provided by Dr A.F. Gazdar and Dr H. Oie (NCI-Navy Medical Oncology Branch, NIH, Bethesda, MD). All cells were maintained in Dulbecco's modified Eagle's medium (DMEM) supplemented with $10 \%$ fetal bovine serum (FBS) and antibiotics (100 U/ml penicillin and $100 \mu \mathrm{g} / \mathrm{ml}$ streptomycin). These cells were grown in a humidified atmosphere of $5 \% \mathrm{CO}_{2}-95 \%$ air at $37^{\circ} \mathrm{C}$.

MTT assay. The cell growth inhibition by chemotherapeutic agents was determined by an MTT assay. Cells were counted with a hematocytometer, and $3 \times 10^{4}$ cells were incubated in $100 \mu \mathrm{l}$ of medium containing the indicated drugs for $72 \mathrm{~h}$ using 96-well flat-bottom multiplates (Nalge Nunc International K. K., Denmark). After 72 h, $20 \mu \mathrm{g}$ of MTT in $10 \mu \mathrm{l}$ PBS was added to each well and incubation was performed for an additional $4 \mathrm{~h}$. Thereafter, $100 \mu 1$ of $0.04 \mathrm{~N}$ $\mathrm{HCl}$ in 2-propanol was added and the multiplates were incubated overnight to solubilize the MTT formazan crystal. The absorbance of each well was measured at a $570-\mathrm{nm}$ wavelength (reference $650 \mathrm{~nm}$ ) using a scanning multi-well spectrophotometer (MPR A4i, Tosoh Co., Tokyo, Japan).

Isobologram analysis. The combination effect of the indicated agents was analyzed by isobologram analysis, as described previously (19). We used the concentration producing $50 \%$ inhibition of cell growth $\left(\mathrm{IC}_{50}\right)$ to evaluate dose-response interactions.

Cell lysis, immunoprecipitation and Western blot analysis. Cells were lysed in a modified radioimmune precipitation buffer ( $1 \%$ Triton $\mathrm{X}-100,0.1 \%$ SDS, $0.1 \%$ sodium deoxycholate, $100 \mathrm{mM} \mathrm{NaCl}, 10 \mathrm{mM}$ Tris-HCl, $\mathrm{pH}$ 7.5, $2 \mathrm{mM}$ EDTA, $10 \mu \mathrm{g} / \mathrm{ml}$ leupeptin, $1 \mathrm{mM}$ phenylmethylsulfonyl fluoride, $10 \mathrm{mM} \mathrm{NaF}, 40 \mathrm{mM}$ B-glycerophosphate and $2 \mathrm{mM}$ $\mathrm{Na}_{3} \mathrm{VO}_{4}$ ) and insoluble material was removed by centrifugation. Protein concentration was determined by means of a Bio-Rad Protein assay (Bio-Rad, CA) and lysates containing $50 \mu \mathrm{g}$ of total cellular protein or immunoprecipitates with the indicated antibodies were analyzed by Western blotting after SDS-polyacrylamide gel (10\%) electrophoresis and transferred to a membrane (GE Healthcare UK Ltd). The membrane was blocked in PBS with $0.05 \%$ Tween-20 (PBST) containing $4 \%$ bovine serum albumin (BSA) for $1 \mathrm{~h}$ at $4^{\circ} \mathrm{C}$.

After blocking, the membrane was incubated in primary antibody (1X PBST, containing 4\% BSA, 1:1,000 antibody) overnight at $4^{\circ} \mathrm{C}$. The membrane was then washed three times with PBST. The immunoblots were incubated for $1 \mathrm{~h}$ in a 1:20,000 dilution of goat anti-rabbit or anti-mouse $\mathrm{IgG}$ coupled with horseradish peroxidase as a secondary antibody (Cell Signaling Technology) in PBS and then washed three times with PBST. Finally, each protein was detected using an enhanced chemiluminescence detection system (ECL, GE Healthcare UK Ltd). Antibody against Akt, phospho-Akt (Ser473), c-Kit, insulin-like growth factor I receptor (IGF-IR) and phospho-Src-family (Tyr416) were purchased from Cell Signaling Technology. Anti-c-Src (B12) antibody was purchased from Santa Cruz Biotechnology. Anti-phosphotyrosine antibody (4G10) was purchased from Upstate Biotechnology. Anti- $\beta$-actin antibody was purchased from Sigma, Tokyo, Japan.

Immunohistochemical analysis. Nineteen human SCLC tissue samples were obtained from surgeries performed between 1980 and 2005 at Matsue National Hospital, Matsue, Japan. None of the patients had received preoperative therapies. Resected specimens and cells from the N417 cell line were fixed in 10\% neutral-buffered formalin and embedded in paraffin. The sections $(3 \mu \mathrm{m})$ were dewaxed, rehydrated and then immersed in $0.6 \%$ hydrogen peroxide in methanol for $30 \mathrm{~min}$ to block endogenous peroxidase. Heat pretreatment was used for antigen retrieval. Non-specific binding of the primary antibody was blocked by incubating the slides in the blocking serum for $20 \mathrm{~min}$. The slides were incubated with the primary antibody, anti-Src rabbit monoclonal antibody (1:800; Cell Signaling Technology, Inc.), at $4^{\circ} \mathrm{C}$ overnight. The immunoreaction was visualized with 3,3'-diaminobenzidine. The staining results were measured semiquantitatively on a scale of $3+, 2+, 1+$ and 0 . To qualify as $3+, 2+$ and $1+$, immunoreaction of $100 \%, \geq 70 \%$ or $<70 \%$ of tumor cells had to be observed, respectively. The semiquantification was evaluated by two independent pathologists. 
A
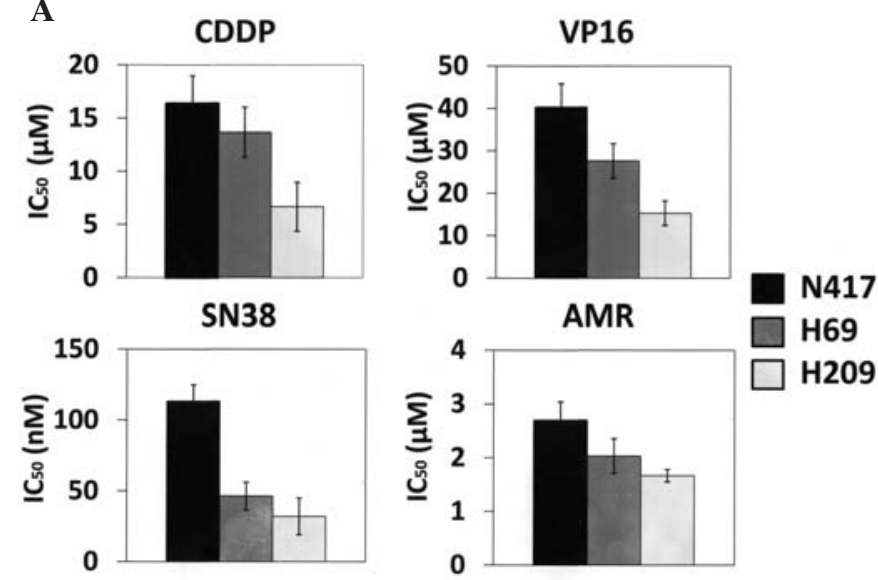

$\mathbf{B}$ N417 H69 H209

p-Akt

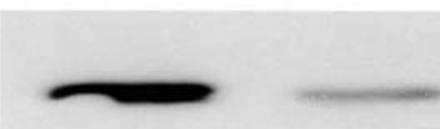

Akt

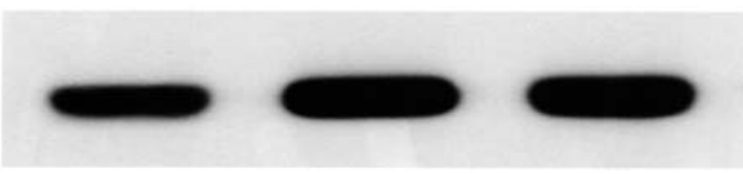

Figure 1. Sensitivity toward chemotherapeutic agents and Akt activity in small cell lung cancer cells. (A) N417, H69 and H209 cells were treated with cisplatin (CDDP), etoposide (VP16), SN38 or amrubicin (AMR) for $72 \mathrm{~h}$. The concentration producing $50 \%$ inhibition of cell growth $\left(\mathrm{IC}_{50}\right)$ was determined by MTT assays. Data are presented as the mean \pm standard deviation of three separate experiments. (B) Total cellular protein $(50 \mu \mathrm{g})$ from the indicated cells was subjected to Western blot analysis with antiphospho-Akt (upper panel) and anti-Akt (lower panel).

\section{Results}

Synergistic cell growth inhibition by the combination of AMR and Akt inhibitor in N417 cells. N417, H69 and H209 cells were treated with various concentrations of CDDP, VP16, SN38 and AMR for $72 \mathrm{~h}$ and $\mathrm{IC}_{50}$ of each cell for each drug was determined by MTT assay. In each drug, the $\mathrm{IC}_{50}$ was high in the order of N417, H69 and H209 cells (Fig. 1A). Because the activation of Akt is known to promote drug resistance of cancer cells to chemotherapeutic agents (20), we examined the phosphorylation state of Akt in these three cell lines by Western blot analysis. The phosphorylation state of Akt was high in the order of N417, H69 and H209 cells (Fig. 1B). To evaluate the function of Akt in drug sensitivity of SCLC cells, we tested the interaction between an Akt inhibitor, LY294002, and chemotherapeutic agents in Akt-activated N417 cells. Fifty micro-molar of LY294002 effectively suppressed Akt phosphorylation (Fig. 2A) and up to this concentration of LY294002 was used to evaluate drug interaction. As shown in Fig. 2B, the combination of LY294002 and AMR exerted synergistic cell growth inhibition in N417 cells, whereas only
A

LY294002 ( $\mu \mathrm{M})$

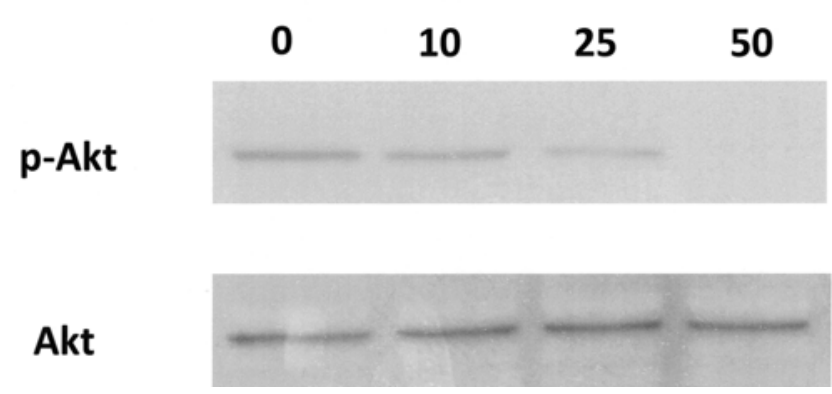

B
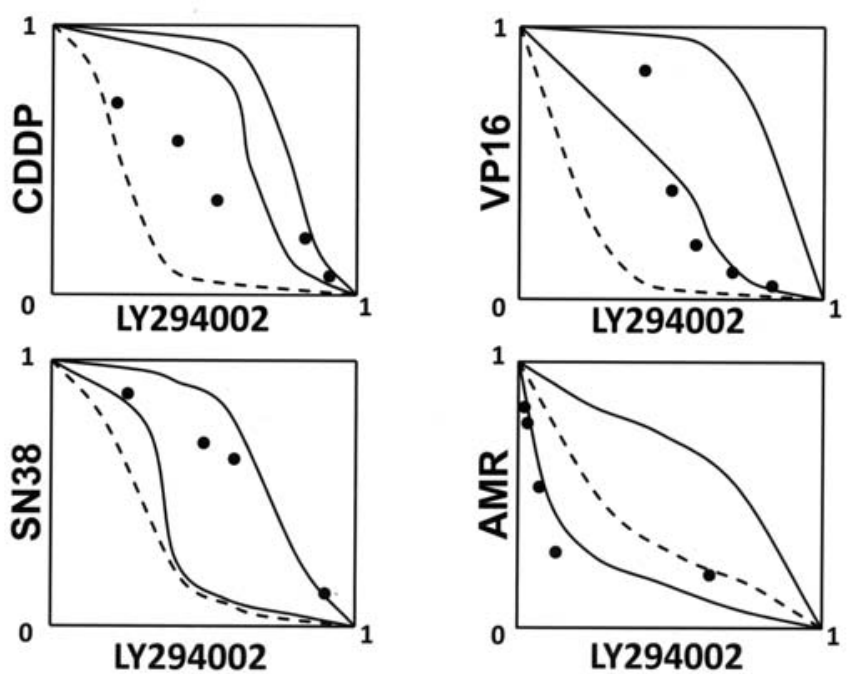

Figure 2. Combination effects of LY294002 and chemotherapeutic agents in N417 cells. (A) N417 cells were treated with the indicated concentrations of LY294002 for $5 \mathrm{~h}$. Total cellular protein $(50 \mu \mathrm{g})$ from N417 cells lysate was subjected to Western blot analysis with anti-phospho-Akt (upper panel) and anti-Akt antibody (lower panel). (B) N417 cells were treated with a combination of LY294002 and cisplatin (CDDP), etoposide (VP16), SN38 or amrubicin (AMR) for $72 \mathrm{~h}$. The combination effects were evaluated with isobologram analysis. The envelopes of additivity are defined by three isoeffect lines constructed from the dose-response curves of the single agents. The concentration producing $50 \%$ cell growth inhibition $\left(\mathrm{IC}_{50}\right)$ of LY294002, CDDP, VP16, SN38 or AMR alone is expressed as 1 on the ordinate and the abscissa, respectively. The plotted data points show the relative values of the concentrations producing $\mathrm{IC}_{50}$.

additive interactions were observed in the combination of LY294002 with CDDP, VP16 or SN38.

Effects of a tyrosine kinase inhibitor on Akt activity and drug interactions with AMR in N417 cells. To clarify the mechanism by which Akt is activated in N417 cells, we compared the pattern and intensity of tyrosine-phosphorylated proteins between N417 and H209 cells using 4G10 antiphospho-tyrosine (PY) antibody. Expression of tyrosinephosphorylated proteins was higher in N417 cells than in H209 cells and the pattern of tyrosine-phosphorylated proteins was different between these cells (Fig. 3A). Furthermore, a non-specific tyrosine kinase inhibitor, genistein, concentration-dependently suppressed Akt activity in the concentration range $<200 \mu \mathrm{M}$ (Fig. 3B). Genistein at these concentrations showed synergistic growth inhibition of N417 cells in the combination with AMR (Fig. 3C). These 
A

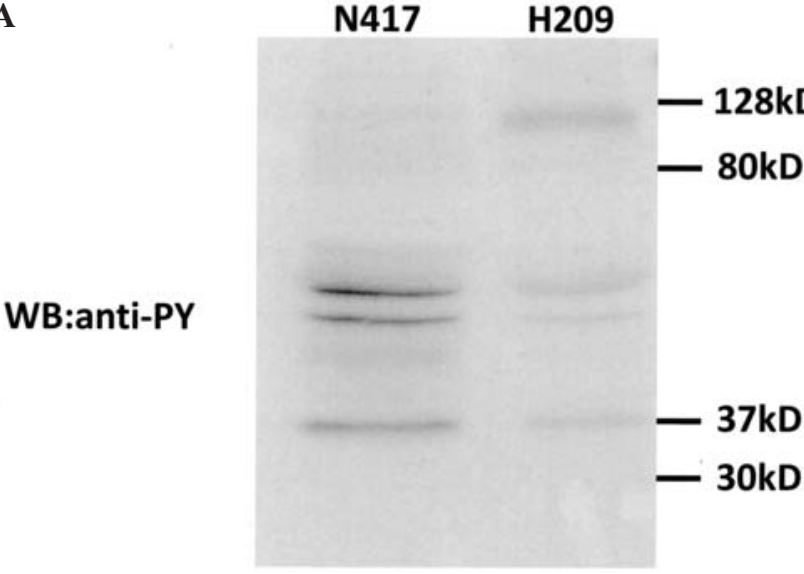

WB: $\beta$-actin

B
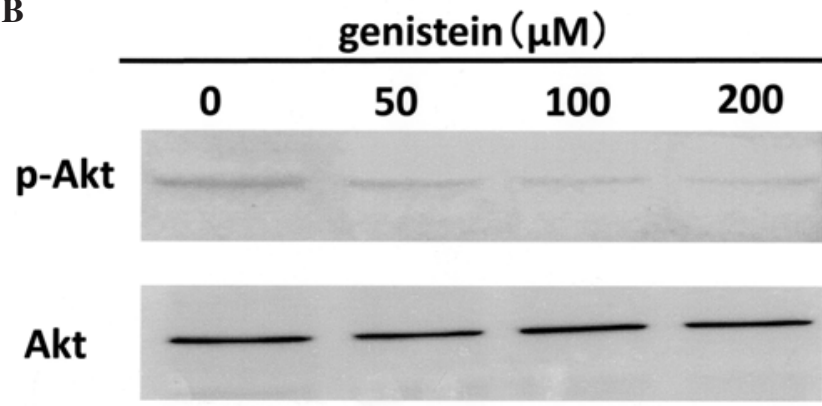

C

1
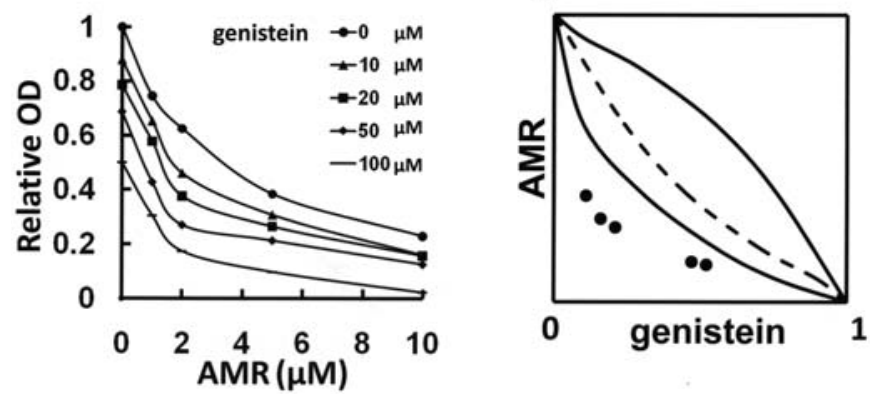

Figure 3. Effect of a tyrosine kinase inhibitor on Akt activity and drug interaction with amrubicin (AMR) in N417 cells. (A) Total cellular protein $(50 \mu \mathrm{g})$ from N417 cells and $\mathrm{H} 209$ cells lysate was subjected to Western blot analysis with anti-phosphotyrosine (PY), clone 4G10 or ß-actin antibody. (B) N417 cells were treated with the indicated concentrations of genistein for $5 \mathrm{~h}$. Total cellular protein $(50 \mu \mathrm{g})$ from the cell lysate was subjected to Western blot analysis with anti-phospho-Akt (upper panel) and anti-Akt antibody (lower panel). (C) N417 cells were treated with a combination of genistein and AMR for $72 \mathrm{~h}$. Dose-response curves were plotted on the basis of the data derived from MTT assay. The survival cell fraction was expressed as the relative optical density (OD) in reference to that of the untreated cells. The combination effects were evaluated with isobologram analysis. The envelopes of additivity are defined by three isoeffect lines constructed from the dose-response curves of the single agents. The concentration producing $50 \%$ cell growth inhibition $\left(\mathrm{IC}_{50}\right)$ of AMR and genistein alone is expressed as 1 on the ordinate and the abscissa, respectively. The plotted data points show the relative values of the concentrations producing $\mathrm{IC}_{50}$.

observations strongly suggested that certain tyrosine kinases may contribute to Akt activation in N417 cells and its inhibition may sensitize SCLC cells to AMR.
A

N417

H209

IP: IGF-IR WB : anti-PY

IP: IGF-IR

WB: IGF-IR

WB: $\beta$-actin

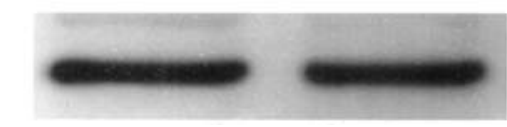

B

N417

H209

IP: c-Kit

WB: c-Kit

WB: $\beta$-actin

C

N417

H209

\section{IP: c-Src \\ WB: c-Src}

\section{WB: $\beta$-actin}

Figure 4. Activation state or expression of insulin-like growth factor I receptor (IGF-IR), c-Kit and c-Src in N417 and H209 cells (A, B and C, respectively). The immunoprecipitate (IP) of the indicated protein from $1 \mathrm{mg}$ total cellular protein or $50 \mu \mathrm{g}$ total cellular protein from the same cell lysate of N417 and H209 cells was subjected to Western blot (WB) analysis with the antibody against phosphotyrosine (PY), IGF-IR, c-Kit, c-Src, phospho-Src or B-actin antibody.

Effect of c-Src inhibitor on Akt activity and drug interaction with AMR in N417 cells. In previous studies, it has been proposed that the autocrine loop performs an important function in the proliferation of SCLC cells (21). c-Kit, IGF-IR and $\mathrm{c}-\mathrm{Src}$ are reported as tyrosine kinases that participate in the autocrine loop of SCLC cells (21). To seek what tyrosine kinase is activated in N417 cells, we evaluated the expression or the activation states of IGF-IR, c-Kit and c-Src by Western blot analysis, comparing the results with those in H209 cells. Although IGF-IR was expressed in N417 cells at a level comparable to that in $\mathrm{H} 209$ cells, the phosphorylation level in N417 cells was extremely low (Fig. 4A) and the expression of c-Kit was hardly detected in N417 cells in comparison with H209 cells (Fig. 4B). c-Src was expressed in both cell lines, but judging from phosphorylation (Tyr416) it is more active in N417 than in H209 cells (Fig. 4C). 
A

\begin{abstract}
IP: c-Src
WB: $p$-Src

IP: c-Src
\end{abstract} \\ WB: c-Src \\ WB: $\beta$-actin}

p-Akt

Akt

C

\section{IP: c-Src \\ WB: $p-S r c$ \\ IP: c-Src \\ WB: c-Src \\ WB: $\beta$-actin}

\section{p-Akt}

Akt
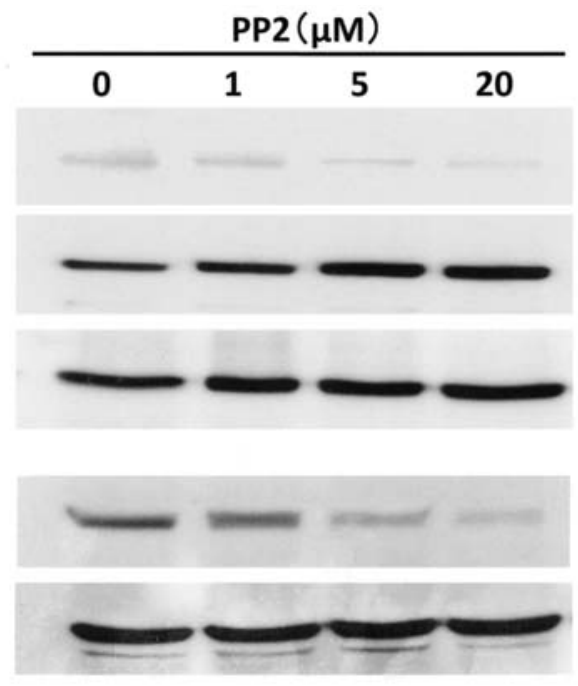

\begin{tabular}{lccc}
\multicolumn{4}{c}{ dasatinib $(\mathrm{nM})$} \\
\hline 0 & 50 & 100 & 500
\end{tabular}
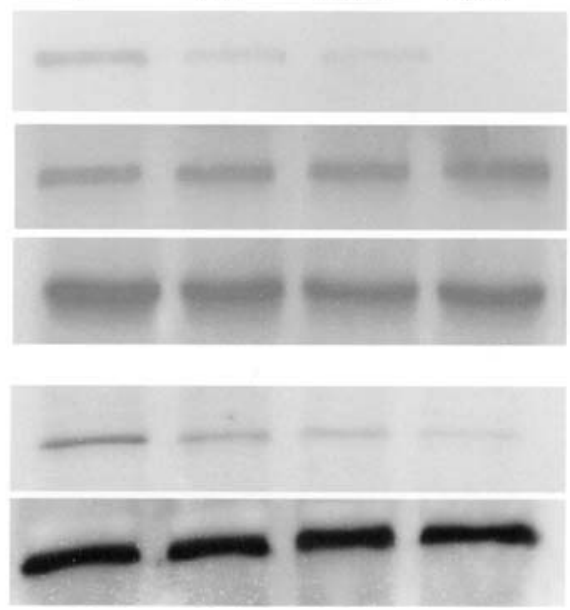

B
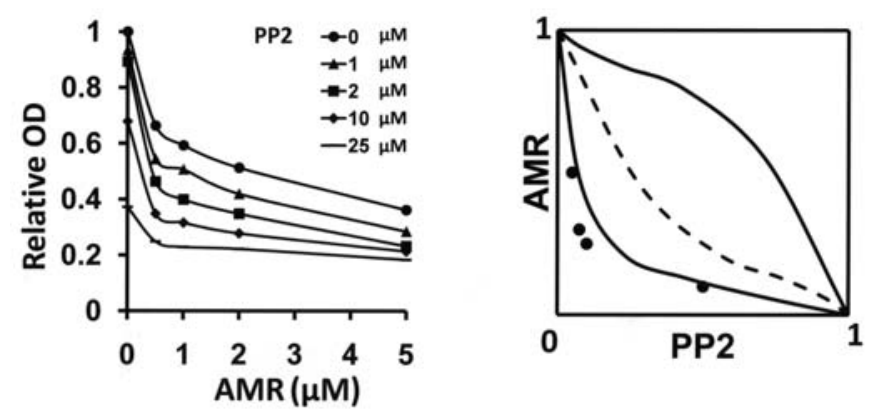

D
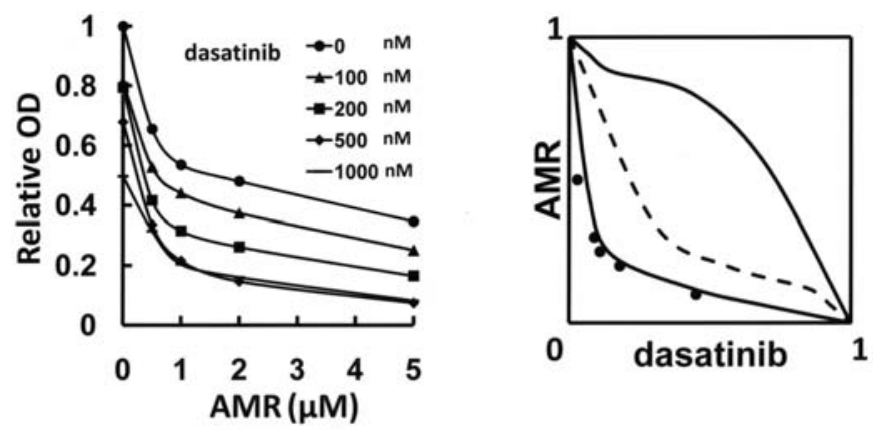

Figure 5. Effect of PP2 and dasatinib on Akt activity and synergistic interaction with amrubicin (AMR) in N417 cells. (A and C) N417 cells were treated with the indicated concentrations of PP2 or dasatinib for $5 \mathrm{~h}$. c-Src was immunoprecipitated (IP) from $1 \mathrm{mg}$ of total cellular protein by anti-c-Src and subjected to Western blot (WB) analysis with anti-phospho-Src (Tyr416) or c-Src. Total cellular protein $(50 \mu \mathrm{g})$ from the same cell lysate was subjected to Western blot analysis with anti-phospho-Akt (p-Akt), anti-Akt or anti-ß-actin antibody. (B and D) N417 cells were treated by a combination of PP2 or dasatinib with AMR for $72 \mathrm{~h}$. Dose-response curves were plotted on the basis of the data derived from MTT assay. The survival cell fraction was expressed as the relative optical density (OD) in reference to that of the untreated cells. The combination effects were evaluated with isobologram analysis. The envelopes of additivity are defined by three isoeffect lines constructed from the dose-response curves of the single agents. The concentration producing $50 \%$ cell growth inhibition (IC ${ }_{50}$ ) of PP2, dasatinib or AMR alone is expressed as 1 on the ordinate or the abscissa. The plotted data points show the relative values of the concentrations producing $\mathrm{IC}_{50}$.

To confirm the link between c-Src and Akt activity, we utilized a c-Src kinase inhibitor, PP2, which effectively suppressed Akt phosphorylation in parallel with the inhibition of c-Src activity in N417 cells (Fig. 5A). Furthermore, similar to LY294002 and genistein, PP2 showed synergistic growth inhibition of N417 cells in the combination with AMR (Fig. 5B).

Considering c-Src-targeted therapy in the treatment of SCLC, we examined the effect of dasatinib, which is a clinically available c-Src inhibitor (22), on c-Src and Akt activity, and the drug interaction of dasatinib with AMR in N417 cells. As expected, like PP2, dasatinib inhibited the phosphorylation of c-Src and Akt in parallel (Fig. 5C) and exerted synergistic cell growth inhibition in the combination with AMR in N417 cells (Fig. 5D).
Immunohistochemical analysis of Src expression in resected tissue samples. We evaluated the expression of c-Src in 19 resected human SCLC tissue samples and N417 cells and observed positive membranous and/or cellular immunoreactions in 17 of 19 tissue samples in various degrees. Representative immunohistochemical results for $\mathrm{c}-\mathrm{Src}$ expression are shown in Fig. 6. Fig. 6A indicates an extremely high level of c-Src expression $(3+)$ in a case with neuroendocrine proliferation. Four of 19 tissue samples showed $3+$ immunoreaction. Fig. 6B indicates a moderate level of c-Src expression (2+). Six of 19 tissue samples showed $2+$ immunoreaction. Fig. 6C indicates a mild level of c-Src expression (1+). Seven of 19 tissue samples showed 1+ immunoreaction. Two tissue samples showed no immunoreaction for c-Src (-) (Fig. 6D). Immunoreaction for c-Src was 


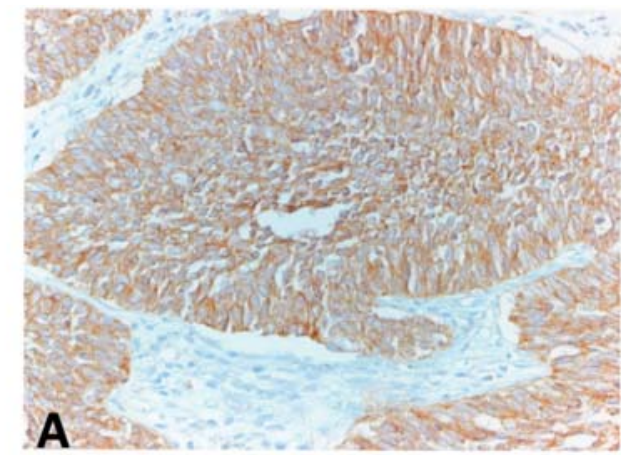

Case 1: 3+

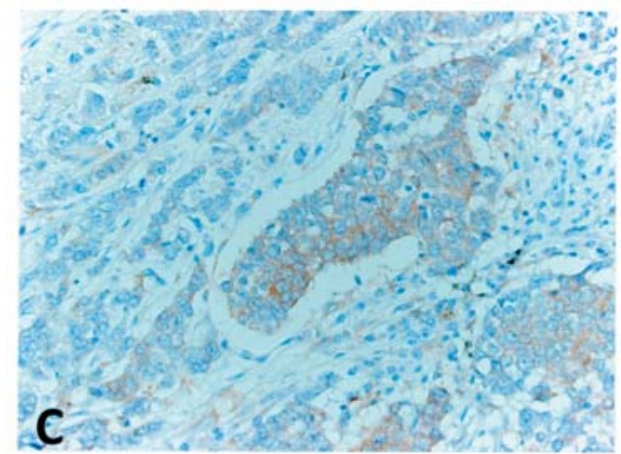

Case 3: 1+

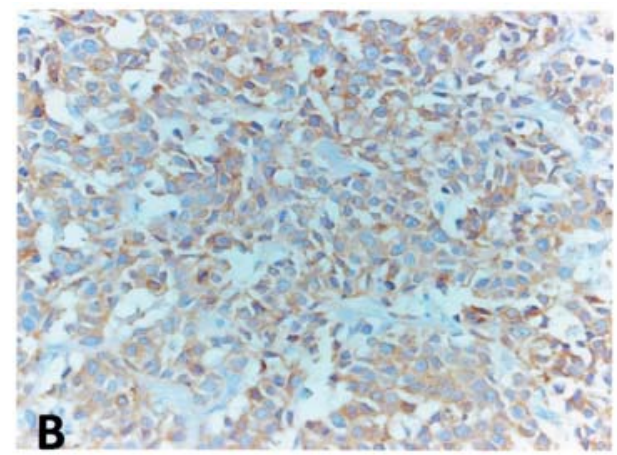

Case 2: 2+

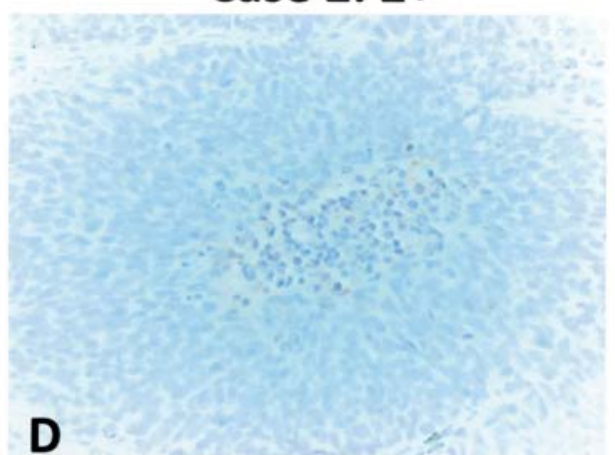

Case 4: -

Figure 6. Immunohistochemical staining for c-Src expression (Magnification: x400). (A to D) Representative c-Src immunohistochemistry scoring in four human SCLC cases. Qualifications as 3+,2+, 1+ and - immunoreaction of $100 \%, \geq 70 \%,<70 \%$ or $0 \%$ of tumor cells, respectively.

not found in histologically normal lung tissues. N417 cells also showed clearly membranous immunoreaction (Fig. not shown).

In addition, we attempted to assess c-Src activity in tumors using active form-specific anti-phospho-Src antibody. In spite of clear detection of phospho-Src in Western blot analysis, we could not detect this active form of c-Src in a cell block of $\mathrm{N} 417$ cells fixed in formalin and embedded in paraffin as a positive control or in tumor samples (data not shown), suggesting that usual procedures for pathological diagnosis are not suitable for the detection of phospho-Src.

\section{Discussion}

Our goal in this study was to clarify whether Akt activity is related to chemo-resistance and to improve the sensitivity of SCLC cells to the current standard cytotoxic agents with potential molecular-targeted drugs that are expected to suppress Akt activity through tyrosine kinase inhibition. We found that Akt activity is strongly related to the sensitivity to AMR among standard chemotherapeutic agents tested in N417 cells. Furthermore, our observations in this study suggest that inhibition of c-Src, which is often highly expressed in SCLC tumors, leads to Akt suppression and c-Src-suppressing agents, including dasatinib, interact synergistically with AMR.

Using three SCLC cell lines with three different levels of Akt activity, we compared $\mathrm{IC}_{50}$ for representative chemotherapeutic agents and assessed the growth inhibitory interaction between these drugs and the Akt inhibitor LY294002. Although $\mathrm{IC}_{50}$ for all chemotherapeutic agents tested seemed to be positively correlated with Akt activity, judging from isobologram analysis, we observed a synergistic interaction of LY294002 in combination with AMR, but not with CDDP, VP16 or SN38 in N417 cells. These observations suggest that Akt inhibition may enhance the cytotoxicity of chemotherapeutic agents in a drug-specific manner. Since tyrosine kinases are major upstream regulators of Akt activity, it is expected that suppression of tyrosine kinase activity will lead to Akt inhibition $(23,24)$. Indeed, there is a clear difference in pattern and intensity of tyrosine-phosphorylated proteins between Akt-activated N417 and Akt-inactive H209 cells. Furthermore, a non-specific tyrosine kinase inhibitor, genistein, suppressed Akt activity in N417 cells and exerted synergistic growth inhibitory activity in the concentration range of Akt inhibition when combined with AMR. These observations strongly support the possibility that suppression of certain tyrosine kinases leads to Akt suppression and enhances AMR cytotoxicity.

Several tyrosine kinases are proposed to be candidates as target molecules in the treatment of SCLC (25). They include c-Kit, IGF-IR and c-Src $(21,25)$. Among them, only c-Src was more activated in N417 cells compared with H209 cells. A specific inhibitor of c-Src, PP2, and a Src family kinaseinhibiting multi-tyrosine kinase inhibitor, dasatinib, effectively suppressed Akt activity in parallel with c-Src inhibition, indicating that $\mathrm{c}-\mathrm{Src}$ is one of the important upstream tyrosine kinases of Akt in N417 cells.

Although we evaluated the association between Akt and c-Src activity only in N417 cells under normal culture conditions, there is evidence indicating that c-Src functions in the autocrine and paracrine loops in other SCLC cell lines. For example, c-Src activity is essential for stem cell factor-induced 
mitogen-activated protein (MAP) kinase activation in H526 cells (26). PI3K/Akt and c-Src are activated by polypeptide growth factors such as stem cell factor, and inhibition of c-Src leads to the suppression of stem cell factor-induced PI3K/Akt activation in H69 cells (24). Several neuropeptides such as gastrin-releasing peptide and bradykinin are proposed to act through the autocrine growth loop in SCLC (27) and these neuropeptides activate $\mathrm{c}$-Src and another tyrosine kinase, Pyk2, through G-protein-coupled receptor in H69 and H510 cells (21). Activation of c-Src leads to Akt stimulation (24). Accordingly, given the autocrine mechanism and c-Src expression in SCLC tumors, Akt should be activated through c-Src in vivo.

In terms of c-Src expression in SCLC tumors, we found this protein in 17 out of 19 samples in immunohistochemical analysis. The detection of c-Src in SCLC tumors is significant, since surgical resection of SCLC is extremely rare. Regarding c-Src expression, to our knowledge there is only one study in which c-Src protein was found in 4 out of 4 cases of SCLC (28). Considering all of these findings, it is valid to propose that c-Src is a promising molecular target in the treatment of SCLC because of its frequent aberrant expression and putative activation in the autocrine loop.

Considering c-Src-targeted therapy as a possible treatment of SCLC, our observations in this study may be useful. At present, specific inhibitors for Akt or c-Src are not clinically available, whereas dasatinib is utilized in the treatment of chronic myelogenous leukemia (CML) (29) and gastrointestinal stromal tumors (GIST) (30), and potently inhibits c-Src activity in addition to Bcr-Abl, c-Kit and platelet-derived growth factor receptor (PDGFR) at a clinically achievable concentration (31). Thus, we propose dasatinib as a clinically available c-Src inhibitor in the therapeutic strategies for treating SCLC. Furthermore, even though imatinib is not effective against SCLC $(16,17,32)$, this does not necessarily mean that the c-Kit-mediated intracellular signal is not functioning in SCLC in vivo. There is a possibility that c-Kit as one of the tyrosine kinases in SCLC is activated, and simultaneous inhibition of c-Kit and c-Src by dasatinib might lead to more effective suppression of intracellular signals including Akt.

Retinoblastoma $(\mathrm{Rb})$ protein is deficient in a majority of SCLC cases $(33,34)$. It is possible that this mutational inactivation of $\mathrm{Rb}$ makes MAP kinase activation dispensable for the growth of SCLC (35). Since the suppression of Akt inhibits cell proliferation, at least partially, through $\mathrm{Rb}$ activation (23), Akt inhibition by tyrosine kinase inhibitor may not be sufficient for tumor growth suppression in Rb-deficient SCLC. In this case, the combination of an Akt-suppressing agent and a conventional cytotoxic drug is postulated. Aktsuppressing agents (i.e., LY294002, genistein, PP2 and dasatinib) consistently interacted with AMR synergistically in this study. The suppression of Akt is reported to enhance the cytotoxicity of doxorubicin in other systems $(36,37)$. These observations suggest that AMR is a suitable cytotoxic drug for the combination with an Akt-suppressing agent including c-Src inhibitors in the treatment of SCLC.

Recently, several tyrosine kinase inhibitors were introduced for the treatment of malignant tumors and provided clinical benefits. Although a number of potential molecular targets including tyrosine kinase are listed in SCLC (25), molecular targeted therapy remains to be developed in the treatment of SCLC.

In conclusion, we propose that Akt suppression enhances the cytotoxicity of AMR and for the purpose of Akt suppression, c-Src, which is aberrantly expressed, is a promising target in SCLC.

\section{References}

1. Simon GR and Turrisi A: Management of small cell lung cancer: ACCP evidence-based clinical practice guidelines (2nd edition). Chest 132: 324S-339S, 2007.

2. Noda K, Nishiwaki Y, Kawahara M, Negoro S, Sugiura T, Yokoyama A, Fukuoka M, Mori K, Watanabe K, Tamura T, Yamamoto $\mathrm{S}$ and Saijo N: Irinotecan plus cisplatin compared with etoposide plus cisplatin for extensive small-cell lung cancer. N Engl J Med 346: 85-91, 2002.

3. Hanna N, Bunn PA Jr, Langer C, Einhorn L, Guthrie T Jr, Beck T, Ansari R, Ellis P, Byrne M, Morrison M, Hariharan S, Wang B and Sandler A: Randomized phase III trial comparing irinotecan/ cisplatin with etoposide/cisplatin in patients with previously untreated extensive-stage disease small-cell lung cancer. J Clin Oncol 24: 2038-2043, 2006.

4. Schiller JH: Topotecan in small cell lung cancer. Semin Oncol 24: S20-S27-S20-S33, 1997.

5. von Pawel J, Schiller JH, Shepherd FA, Fields SZ, Kleisbauer JP, Chrysson NG, Stewart DJ, Clark PI, Palmer MC, Depierre A, Carmichael J, Krebs JB, Ross G, Lane SR and Gralla R: Topotecan versus cyclophosphamide, doxorubicin, and vincristine for the treatment of recurrent small-cell lung cancer. J Clin Oncol 17: 658-667, 1999.

6. Argiris A and Murren JR: Advances in chemotherapy for small cell lung cancer: single-agent activity of newer agents. Cancer J 7: 228-235, 2001

7. Ettinger DS: Amrubicin for the treatment of small cell lung cancer: does effectiveness cross the Pacific? J Thorac Oncol 2: 160-165, 2007.

8. Fischer B and Arcaro A: Current status of clinical trials for small cell lung cancer. Rev Recent Clin Trials 3: 40-61, 2008.

9. Talapatra S and Thompson CB: Growth factor signaling in cell survival: implications for cancer treatment. J Pharmacol Exp Ther 298: 873-878, 2001.

10. Vivanco I and Sawyers CL: The phosphatidylinositol 3-Kinase AKT pathway in human cancer. Nat Rev Cancer 2: 489-501, 2002.

11. Franke TF, Hornik CP, Segev L, Shostak GA and Sugimoto C: PI3K/Akt and apoptosis: size matters. Oncogene 22: 8983-8998, 2003.

12. Choi Y, Zhang J, Murga C, Yu H, Koller E, Monia BP Gutkind JS and Li W: PTEN, but not SHIP and SHIP2, suppresses the PI3K/Akt pathway and induces growth inhibition and apoptosis of myeloma cells. Oncogene 21: 5289-5300, 2002.

13. Blackhall FH, Pintilie M, Michael M, Leighl N, Feld R, Tsao MS and Shepherd FA: Expression and prognostic significance of kit, protein kinase $\mathrm{B}$, and mitogen-activated protein kinase in patients with small cell lung cancer. Clin Cancer Res 9: 2241-2247, 2003 .

14. Kim D, Cheng GZ, Lindsley CW, Yang H and Cheng JQ: Targeting the phosphatidylinositol-3 kinase/Akt pathway for the treatment of cancer. Curr Opin Investig Drugs 6: 1250-1258, 2005.

15. Wang WL, Healy ME, Sattler M, Verma S, Lin J, Maulik G, Stiles CD, Griffin JD, Johnson BE and Salgia R: Growth inhibition and modulation of kinase pathways of small cell lung cancer cell lines by the novel tyrosine kinase inhibitor STI 571. Oncogene 19: 3521-3528, 2000.

16. Krug LM, Crapanzano JP, Azzoli CG, Miller VA, Rizvi N, Gomez J, Kris MG, Pizzo B, Tyson L, Dunne M and Heelan RT: Imatinib mesylate lacks activity in small cell lung carcinoma expressing c-kit protein: a phase II clinical trial. Cancer 103: 2128-2131, 2005.

17. Dy GK, Miller AA, Mandrekar SJ, Aubry MC, Langdon RM Jr, Morton RF, Schild SE, Jett JR and Adjei AA: A phase II trial of imatinib (ST1571) in patients with c-kit expressing relapsed small-cell lung cancer: a CALGB and NCCTG study. Ann Oncol 16: 1811-1816, 2005. 
18. Johnson BE, Fischer T, Fischer B, Dunlop D, Rischin D, Silberman S, Kowalski MO, Sayles D, Dimitrijevic S, Fletcher C, Hornick J, Salgia R and Le Chevalier T: Phase II study of imatinib in patients with small cell lung cancer. Clin Cancer Res 9: 5880-5887, 2003.

19. Steel GG and Peckham MJ: Exploitable mechanisms in combined radiotherapy-chemotherapy: the concept of additivity. Int J Radiat Oncol Biol Phys 5: 85-91, 1979.

20. Brognard J, Clark AS, Ni Y and Dennis PA: Akt/protein kinase $\mathrm{B}$ is constitutively active in non-small cell lung cancer cells and promotes cellular survival and resistance to chemotherapy and radiation. Cancer Res 61: 3986-3997, 2001.

21. Roelle S, Grosse R, Buech T, Chubanov V and Gudermann T: Essential role of Pyk2 and Src kinase activation in neuropeptideinduced proliferation of small cell lung cancer cells. Oncogene 27: 1737-1748, 2008.

22. Steinberg M: Dasatinib: a tyrosine kinase inhibitor for the treatment of chronic myelogenous leukemia and Philadelphia chromosome-positive acute lymphoblastic leukemia. Clin Ther 29: 2289-2308, 2007.

23. Ma PC, Tretiakova MS, Nallasura V, Jagadeeswaran R, Husain AN and Salgia R: Downstream signalling and specific inhibition of c-MET/HGF pathway in small cell lung cancer: implications for tumour invasion. Br J Cancer 97: 368-377, 2007.

24. Arcaro A, Aubert M, Espinosa del Hierro ME, Khanzada UK, Angelidou S, Tetley TD, Bittermann AG, Frame MC and Seckl MJ: Critical role for lipid raft-associated Src kinases in activation of PI3K-Akt signalling. Cell Signal 19: 1081-1092, 2007.

25. Fischer B, Marinov M and Arcaro A: Targeting receptor tyrosine kinase signalling in small cell lung cancer (SCLC) what have we learned so far? Cancer Treat Rev 33: 391-406, 2007.

26. Warshamana-Greene GS, Litz J, Buchdunger E, Hofmann F, Garcia-Echeverria C and Krystal GW: The insulin-like growth factor-I (IGF-I) receptor kinase inhibitor NVP-ADW742, in combination with STI571, delineates a spectrum of dependence of small cell lung cancer on IGF-I and stem cell factor signaling. Mol Cancer Ther 3: 527-535, 2004

27. Worden FP and Kalemkerian GP: Therapeutic advances in small cell lung cancer. Expert Opin Investig Drugs 9: 565-579, 2000.

28. Mazurenko NN, Kogan EA, Zborovskaya IB and Kisseljov FL: Expression of pp60c-src in human small cell and non-small cell lung carcinomas. Eur J Cancer 28: 372-377, 1992.
29. Tam CS, Kantarjian H, Garcia-Manero G, Borthakur G, O'Brien S, Ravandi F, Shan J and Cortes J: Failure to achieve a major cytogenetic response by 12 months defines inadequate response in patients receiving nilotinib or dasatinib as second or subsequent line therapy for chronic myeloid leukemia. Blood 112: 516-518, 2008.

30. von Mehren M: Beyond imatinib: second generation c-KIT inhibitors for the management of gastrointestinal stromal tumors. Clin Colorectal Cancer 6 (Suppl 1): S30-S34, 2006.

31. Finn RS, Dering J, Ginther C, Wilson CA, Glaspy P, Tchekmedyian N and Slamon DJ: Dasatinib, an orally active small molecule inhibitor of both the src and abl kinases, selectively inhibits growth of basal-type/'triple-negative' breast cancer cell lines growing in vitro. Breast Cancer Res Treat 105: 319-326, 2007.

32. Micke P, Basrai M, Faldum A, Bittinger F, Ronnstrand L, Blaukat A, Beeh KM, Oesch F, Fischer B, Buhl R and Hengstler JG: Characterization of c-kit expression in small cell lung cancer: prognostic and therapeutic implications. Clin Cancer Res 9: 188-194, 2003.

33. Shimizu E, Coxon A, Otterson GA, Steinberg SM, Kratzke RA, Kim YW, Fedorko J, Oie H, Johnson BE, Mulshine JL, et al: RB protein status and clinical correlation from 171 cell lines representing lung cancer, extrapulmonary small cell carcinoma, and mesothelioma. Oncogene 9: 2441-2448, 1994

34. Ookawa K, Shiseki M, Takahashi R, Yoshida Y, Terada M and Yokota J: Reconstitution of the RB gene suppresses the growth of small-cell lung carcinoma cells carrying multiple genetic alterations. Oncogene 8: 2175-2181, 1993.

35. Bondzi C, Litz J, Dent P and Krystal GW: Src family kinase activity is required for Kit-mediated mitogen-activated protein (MAP) kinase activation, however loss of functional retinoblastoma protein makes MAP kinase activation unnecessary for growth of small cell lung cancer cells. Cell Growth Differ 11: 305-314, 2000.

36. Fujiwara Y, Kawada K, Takano D, Tanimura S, Ozaki K and Kohno M: Inhibition of the PI3 kinase/Akt pathway enhances doxorubicin-induced apoptotic cell death in tumor cells in a p53-dependent manner. Biochem Biophys Res Commun 340: 560-566, 2006.

37. Yu HG, Ai YW, Yu LL, Zhou XD, Liu J, Li JH, Xu XM, Liu S, Chen J, Liu F, Qi YL, Deng Q, Cao J, Liu SQ, Luo HS and Yu JP: Phosphoinositide 3-kinase/Akt pathway plays an important role in chemoresistance of gastric cancer cells against etoposide and doxorubicin induced cell death. Int J Cancer 122: 433-443, 2008. 